\title{
Self-Controlled Feedback and Trait Anxiety in Motor Skill Acquisition
}

\author{
Raquel Maia Bokums, Cassio M. Meira Jr., Jaqueline F. O. Neiva, \\ Thaynara Oliveira, Jusselma Ferreira Maia \\ University of Sao Paulo, Sao Paulo, Brazil \\ Email: cmj@usp.br
}

Received February 22 $2^{\text {nd }}, 2012$; revised March 27 $7^{\text {th }}, 2012$; accepted April $28^{\text {th }}, 2012$

\begin{abstract}
This study examined the relationship between trait anxiety (TA) and self-controlled (SC) frequency of feedback in the acquisition of the overhead volleyball serve. Forty-eight adolescent girls performed 240 acquisition trials, with the provision of knowledge of results (KR). After $48 \mathrm{~h}$, they performed 16 transfer no-KR trials. Although no interactions were found on either acquisition or transfer, the high-anxious girls requested more feedback than the low-anxious ones. Also, feedback was requested more after accurate than after inaccurate trials.
\end{abstract}

Keywords: Self-Control; Feedback; Knowledge of Results; Anxiety; Motor Learning

\section{Introduction}

With the purpose of reconciling counterintuitive findings in motor learning (ML), Guadagnoli and Lee (2004) proposed a challenge-point framework (CPF) based on the idea that learning is directly related to the level of challenge imposed by a practice or feedback condition. These authors argued that learning is maximized when a person faces an optimal level of challenge during the process of motor skill acquisition. In contrast, learning will be compromised if the challenge imposed is either too high or too low. The challenge-point created by any given ML situation is determined by the functional difficulty of the task, which results from an interaction between nominal task difficulty, the learner's skill level, and the conditions of practice and/or feedback. The nominal difficulty of a task is a fixed characteristic based on specific perceptual and motor requirements. For example, an underarm volleyball serve has a lower nominal task difficulty than an overhead serve. Thus, the higher the nominal task difficulty, the higher the functional task difficulty and, in turn, the higher the challenge-point of learning. CPF has gained support in the learning of sport (Brady, 2008; Guadagnoli \& Lindquist, 2007) and surgical (Cristancho, Moussa \& Dubrowski, 2010; Gofton, 2006; Hodges, Kuper, \& Phil, 2012; Moulton, Dubrowski, MacRae, Graham, Grober, \& Reznick, 2006) skills, handwriting (Asher, 2006), walking (Domingo \& Ferris, 2009), and in physical therapy (Descarreaux, Passmore, \& Cantin, 2010; Maas, Robin, Hula, Freedman, Wulf, Ballard, \& Schmidt, 2008; Onla-or \& Winstein, 2008). Given that, in the CPF, practice variables have been examined across different types of participants, we believe that investigating people with different levels of trait anxiety (TA) could help to better understand ML processes.

TA, defined as a predisposition of an individual to perceive a wide range of situations that, objectively, are not actually dangerous as threatening (Weinberg \& Gould, 2011), has been pointed out as a personal characteristic that influences motor performance and learning (Schmidt \& Wrisberg, 2008; Wris- berg, 2007). Individuals who have high levels of TA respond to perceived threatening situations with reactions that are disproportionate to the objective danger when compared to low TA individuals (Spielberger, 1972). Although high TA is often associated with negative performance on cognitive tasks (Eysenck, 1992; Eysenck \& Calvo, 1992), there is no evidence of deleterious effects of high TA on motor performance (Calvo \& Ramos, 1989, Experiment 2). Negative effects of high TA on the efficiency of processing are generally greater in concurrent cognitive tasks (Eysenck, Derakshan, Santos, \& Calvo, 2007).

Knowledge of results (KR) is a form of augmented feedback which provides information on the outcome of the movement (Magill, 2011). Self-controlled (SC) frequency of KR gives the learner the opportunity of receiving information only when he or she requests it. Several studies have shown that SC-KR facilitates ML when compared to externally controlled KR schedules (Chiviacowsky \& Wulf, 2002, 2007, 2009; Chiviacowsky et al., 2005, 2008; Janelle et al., 1995, 1997). It has been argued that SC-KR, when compared to yoked (YK) KR (when KR is presented at a frequency yoked to a SC participant's KR requests), engages the leaner in the process of learning more, on account of the freedom it provides to make decisions about some of its aspects. More specifically, SC-KR allows engagement in problem-solving strategies as well as acts as a source of motivation to continue to practice. Self-control is thought to facilitate ML because it enables subjects to test movement strategies (Wulf \& Toole, 1999), to manage practice according to their needs (Chiviacowsky \& Wulf, 2002, 2005), and to perceive themselves more autonomous and thus more motivated during the learning process (Lewthwaite \& Wulf, 2010).

The purpose of this study was to investigate the relationship between TA and SC-KR in the acquisition and transfer of the overhead volleyball serve. Grounded upon CPF and on literature about TA and SC-KR, we hypothesize that low-anxious individuals who self-control their feedbacks will show superior motor learning than their YK and high-anxious counterparts. 


\section{Method}

Forty-eight female students aged between 12 and 14 years $(\mathrm{M}=13.33, \mathrm{SD}=.72)$ were selected from a sample of $134 \mathrm{stu}-$ dents to take part in the study. All participants filled out the Brazilian version (Biaggio \& Natalício, 2003) of the State-Trait Anxiety Inventory (STAI, Spielberger, Gorsuch, Lushene, Vagg, \& Jacobs, 1983) and were organized into three categories, based on their TA scores: low TA $(31-42)$, intermediate TA (43 - 51), and high TA (52 - 63). For the purposes of the current study, only low and high TA individuals were asked to participate in this study. Participants were then semi-randomly assigned to one of four experimental groups: self-control/high trait anxiety (SC-HighTA), yoked/high trait anxiety (YKHighTA), self-control/low trait anxiety (SC-LowTA), and yoked/low trait anxiety (YK-LowTA). The parents/tutors of all participants signed consent forms, approved by the University Ethics Board, prior to their participation. None of the participants had prior experience at the task.

The task, an overhead volleyball serve, is defined as having high nominal difficulty (Guadagnoli \& Lee, 2004) due to various perceptual motor and physical fitness abilities underlying it, such as anticipation timing, multi-limb coordination, speed of arm movement, gross body coordination, arm explosive strength (Fleishman \& Quaintance, 1984), static balance, visual acuity, visual tracking, and eye-hand coordination (Magill, 2011). All serves were performed with the dominant hand and aimed toward a circular target, 18 meters in diameter. The task's goal was to serve the ball on the target's center (10 points), which measured one meter in diameter; the other areas measured one meter in diameter more than the next smallest area, assuming values of 8,6, 4 and 2, respectively. Zero was the score given for a ball which did not fly over the net or for a ball which landed outside the target. In case a ball had landed on the borderline, it was given the score of the area whose value was higher. All borderlines were $5 \mathrm{~cm}$ wide. To perform the task, participants stood behind the service line, diagonally to the net.

Participants performed 240 acquisition trials, equally distributed over five days of practice. Each practice day consisted of two blocks of 24 trials. Sixteen transfer trials were administered 48 hours after the end of acquisition. Prior to the start of the experiment, each participant watched an instructional video on how to perform the overhead volleyball serve, which was shown as many times as the participant wanted and were given information about task goal, scoring system, and basic procedures of receiving KR. During acquisition, the serves were performed from a fixed area on the left side of the court, at a distance of five meters from the net. During transfer, participants served from the same distance, but from the right side of the court. The net's height was set at 2 meters.

During acquisition, terminal KR was provided verbally about both direction (left, right, near or far) and magnitude (10, 8, 6, 4, 2 , and 0 ). No KR was given during transfer. The participants in the SC condition were informed that they would control the frequency of KR; that is, they would not receive $\mathrm{KR}$, unless they asked for it. The YK participants were informed that they would only receive KR after certain trials. Participants were prevented from seeing where the ball landed on account of a black tarp on the net. Five minutes after the end of acquisition, the participants answered a questionnaire (adapted from Chiviacowsky \& Wulf, 2002) about the preference of receiving KR after accurate (good) or inaccurate (bad) trials.
Data was organized in blocks of 16 trials (average score), totaling 15 acquisition blocks (A1-A15) and one transfer block (T). No missing data or outliers were detected. Analysis involved the comparison among means (analysis of variance). No violations of data distribution or sphericity were detected. For acquisition, we ran a 2 (SC/YK) X 2 (highTA/lowTA) X 2 (initial block-A1/final block-A15) analysis of variance with repeated measures on the last factor. For transfer, a 2 (SC/YK) $\mathrm{X} 2$ (highTA/lowTA) analysis of variance was used. To detect whether participants showed better performance in the trials with or without $\mathrm{KR}$, we ran a 2 (KR trials/no-KR trials) $\mathrm{X} 2$ ( $\mathrm{SC} / \mathrm{YK}$ ) analysis of variance. To compare the levels of anxiety with the frequency of $\mathrm{KR}$ requested in the $\mathrm{SC}$ groups during the first and second halves of acquisition, a 2 (highTA/lowTA) X 2 (first half/second half) analysis of variance was carried out. When appropriate, F-ratios involving repeated measures factors were reported with the Greenhouse-Geisser df adjustment. Partial eta-squared values $\left(\eta^{2}\right)$ were also reported to indicate effect sizes for significant results. Follow-up testing was conducted using Sidak post hoc procedures. For all analyses, alpha was set at .05 . The percentage of responses obtained in the questionnaire regarding good and bad performances from the SC and YK conditions were also described.

\section{Results}

Figure 1 shows the mean values of points obtained by the experimental groups on acquisition and transfer. A significant effect for the main factor "Block" was found between A1 and A15 $\left[\mathrm{F}(1,22)=15.78, p=.001 ; \eta^{2}=.42\right]$, but no significant differences were detected for either the interaction "Group $\mathrm{X}$ Block" or the main factor "Group" on acquisition and transfer.

Regarding the amount of KR requested on the first half of acquisition, high-anxious participants requested more information (170 KRs) than their low-anxious counterparts (65 KRs), albeit the significance was marginal $[\mathrm{F}(2,21)=2.75, p=.069]$. No difference in the amount of KR requested was detected between high (170 KRs) and low (157 KRs) TA participants in the second half of acquisition. Overall, participants asked for KR after 562 out of 11,520 trials $(4.88 \%), 4.07 \%$ in the first and $5.68 \%$ in the second half.

With the purpose of determining whether the participants who practiced under SC and YK conditions showed better results in trials after the presence or absence of KR, the sum of each of these trials in the two acquisition halves were calculated. Regarding trials after which KR was received in the first half of acquisition, SC participants scored 59.1 points, whereas YK participants scored 30.1 points; in the second half of acquisition, SC participants obtained 89 points, while their YK counterparts obtained 48.8 points. With respect to trials after which KR was not received, SC participants achieved 234.9 points, whereas YK ones scored 262.5 in the first half; SC participants obtained 274.9 points, whereas YK ones scored 277.4 points in the second half.

It was also detected that SC participants scored higher than YK participants in the first and second halves of acquisition $[\mathrm{F}(1,46)=2.83 ; p=0.06]$. In contrast, no significant effects were found for the no-KR trials. It is important to report that in no-KR trials (25193 - 61\% of all trials) both SC and YK conditions had higher scores than in KR trials (5446 KRs - 39\% of all trials).

Regarding exclusively to those who SC their KR, 16 (67\%) 


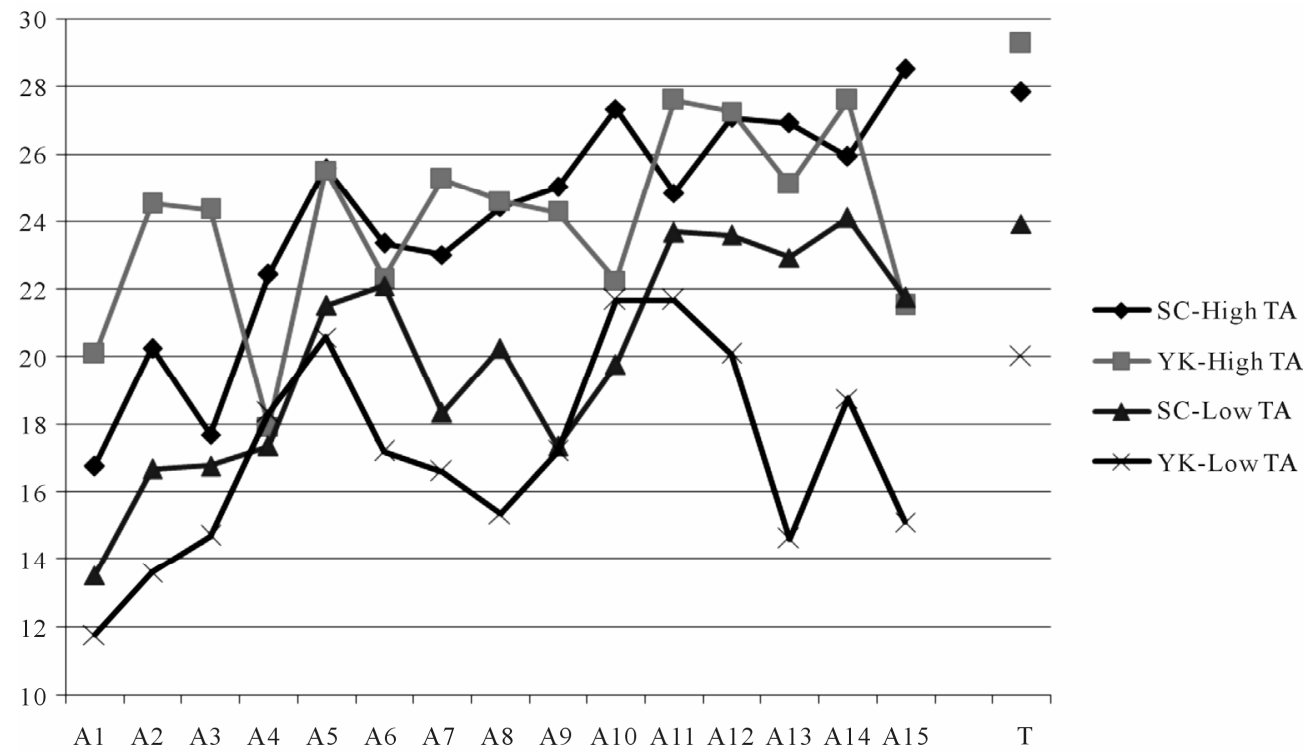

Figure 1.

Average scores (X-axis) of the four experimental groups on acquisition (A1-A15) and transfer (T) (Y-axis).

reported requesting KR after good trials, while $18(75 \%)$ reported that they did not ask for feedback after bad trials.

\section{Discussion}

The results showed no significant interactions between TA and SC-KR. This fact refutes the stated hypothesis that lowanxious individuals who self-control KR would show enhanced learning. Several studies have reported no differences between high and low anxiety levels in response accuracy (Blankstein, Flett, Boase, \& Toner, 1990; Blankstein, Toner, \& Flett, 1989; Calvo, Alamo, \& Ramos, 1990; Calvo \& Ramos, 1989). The lack of differences between SC and YK is quite surprising. Considering that the overhead volleyball serve has a high nominal difficulty, it may be that for tasks with high perceptual and motor requirements, the engagement in active processes of performance evaluation (i.e., elaborative encoding) is elicited by both $\mathrm{SC}$ and externally controlled schedules of KR. It may also be that the effects of SC are offset by the functional difficulty of the task, that is, beginners performing a task with high nominal difficulty. According to CPF (Guadagnoli \& Lee, 2004), if the participants were experts or the task was of low nominal difficult, the likelihood of facing an optimal level of challenge during the process would be higher and, as a result, learning would be maximized.

High-anxious individuals requested more KR than low-anxious individuals. A plausible explanation for this finding is that those who score high in TA, invest in extra processing resources (Calvo \& Ramos, 1989); that is, requesting more information to facilitate drawing attention to their inner resources to cope with task demands (Jones, 1995; Jones \& Swain, 1995; Weinberg \& Gould, 2011). With regard to SC participants, two-thirds of them reported that KR was requested after perceived successful trials (good), a typical finding in current ML literature (Chiviacowsky, 2002, 2005, 2007; Chiviacowsky, Godinho, \& Tani, 2005; Chiviacowsky, Wulf, Medeiros, Kaefer, \& Wally, 2008); this reinforces the importance of KR as a tool to confirm a learner's subjective evaluation of performance.
In addition, $\mathrm{SC}$ participants obtained more points than their $\mathrm{YK}$ counterparts after serves followed by KR.

A central hypothesis of the $\mathrm{CPF}$ is that reduced $\mathrm{KR}$ is beneficial to beginners when learning a task with low levels of nominal difficulty, while frequent $\mathrm{KR}$ is beneficial to beginners when learning a task with high levels of nominal difficulty (Guadagnoli \& Lee, 2004). It was thus expected that SC participants would request frequent $\mathrm{KR}$, but they asked for very little augmented information (one KR at every 20 trials on average). Such a reduced KR schedule helps the development of the learner's autonomy via exploration of inherent feedback (Schmidt \& Lee, 2011; Magill, 2011). The reduced frequency of KR requested by the SC participants of the current study is in line with the pattern that has been reported in the ML literature (Chiviacowsky \& Wulf, 2002, 2007, 2009).

The improvements throughout trials are crucial to quantify the gains in performance and almost certainly can be interpreted as caused by motor learning (Lee, 2011; Schmidt \& Lee, 2011). Our results showed that the amount of points in successive blocks decreased from the initial to the final acquisition block. Moreover, other compelling evidence that learning occurred is the fact that the transfer performances showed by the experimental groups were similar to the performances showed in the final acquisition block (Magill, 2011).

As a concluding remark, we would like to highlight that the literature on anxiety has been differentiating effectiveness from efficiency (Calvo \& Ramos, 1989, 1990; Eysenck, 1979; Eysenck \& Calvo, 1992; Eysenck, Derakshan, Santos, \& Calvo, 2007). While the first is associated with the quality of performance, the latter relates to the relationship between the effectiveness of performance and the effort or resources spent. Efficiency is thought to decrease as more resources are invested to attain a certain level of performance. Given that the negative effects of TA are greater on efficiency than on effectiveness, it is also of great importance that future research includes variables that assess not only effectiveness, but also efficiency. For example, self-preoccupation (or worry) is characterized by concerns over evaluation, failure and expectations of aversive 
consequences (Eysenck, Derakshan, Santos, \& Calvo, 2007) and represents efficiency because it reduces storage and processing capacity and increments on-task effort.

\section{REFERENCES}

Biaggio, M. B., \& Natalício, L. (2003). Manual do inventário de ansiedade traço estado (IDATE). CEPA, Rio de Janeiro.

Brady, F. (2008). The contextual interference effect and sport skills. Perceptual and Motor Skills, 106, 461-472. doi:10.2466/pms.106.2.461-472

Calvo, M. G., \& Ramos, P. M. (1989). Effects of test anxiety on motor learning: The processing efficiency hypothesis. Anxiety Research, 2, 45-55. doi:10.1080/08917778908249325

Calvo, M. G., Alamo, L., \& Ramos, P. M. (1990). Test anxiety, motor performance and learning: Attentional and somatic interference. Personality and Individual Differences, 11, 29-38. doi:10.1016/0191-8869(90)90165-N

Chiviacowsky, S., Godinho, M., \& Tani, G. (2005). Self-controlled knowledge of results: Effects of different schedules and task complexity. Journal of Human Movement Studies, 49, 277-296.

Chiviacowsky, S., \& Wulf, G. (2002). Self-controlled feedback: Does it enhance learning because performers get feedback when they need it? Research Quarterly for Exercise and Sport, 73, 408-415.

Chiviacowsky, S., \& Wulf, G. (2005). Self-controlled feedback is effective if it is based on the learner's performance. Research Quarterly for Exercise and Sport, 76, 42-48. doi:10.5641/027013605X13076330976713

Chiviacowksy, S., \& Wulf, G. (2007). Feedback after good trials enhances learning. Research Quarterly for Exercise and Sport, 78, 4047.

Chiviacowsky, S., Wulf, G., Medeiros, F. L., Kaefer, A., \& Wally, R. (2008). Self-controlled feedback in 10-year old children: Higher feedback frequencies enhance learning. Research Quarterly for Exercise and Sport, 79, 122-127. doi: $10.5641 / 193250308 X 13086753543176$

Cristancho, S. M., Moussa, F., \& Dubrowski, A. (2011). A framework-based approach to designing simulation-augmented surgical education and training programs. American Journal of Surgery, 202, 344-351. doi:10.1016/j.amjsurg.2011.02.011

Descarreaux, M., Passmore, S. R., \& Cantin, V. (2010). Head movement kinematics during rapid aiming task performance in healthy and neck-pain participants: The importance of optimal task difficulty. Manual Therapy, 15, 445-450. doi:10.1016/j.math.2010.02.009

Eysenck, M. W., \& Calvo, M. G. (1992). Anxiety and performance: the processing efficiency theory. Cognition \& Emotion, 6, 409- 434. doi:10.1080/02699939208409696

Eysenck, M. W., Derakshan, N., Santos, R., \& Calvo, M. G. (2007). Anxiety and cognitive performance: Attentional control theory. Emotion, 7, 336-353. doi:10.1037/1528-3542.7.2.336

Fleishman, E. A., \& Quaintance, M. K. (1984). Taxonomies of human performance. Orlando: Academic Press.

Guadagnoli, M. A., \& Lee, T. D. (2004). Challenge point: A framework for conceptualizing the effects of various practice conditions in motor learning. Journal of Motor Behavior, 36, 212-224.
doi:10.3200/JMBR.36.2.212-224

Guadagnoli, M., \& Lindquist, K. (2007). Challenge point framework and efficient learning of golf. International Journal of Sports Science and Coaching, 2, 185-197. doi:10.1260/174795407789705505

Gofton, W. (2006). Factors in optimizing the learning environment for surgical training. Clinical Orthopaedics and Related Research, 449 , 100-107.

Hodges, B. D., Kuper, A., \& Phil, D. (2012). Theory and practice in the design and conduct of graduate medical education. Academic Medicine, 87, 25-33. doi:10.1097/ACM.0b013e318238e 069

Janelle, C. M., Barba, D. A. Frehlich, S. G., Tennant, L. K., \& Cauraugh, H. (1997). Maximizing performance feedback effectiveness through videotape replay and self-controlled learning environment. Research Quarterly for Exercise and Sport, 68, 269-279.

Janelle, C. M., Kim, J., \& Singer, R. N. (1995). Subject-controlled performance feedback of a closed motor skill. Perceptual and Motor Skills, 81, 627-634. doi:10.2466/pms.1995.81.2.627

Jones, G. (1995). More than just a game: Research developments and issues in competitive anxiety in sport. British Journal of Psychology, 86, 449-478. doi:10.1111/j.2044-8295.1995.tb02565.x

Jones, G., \& Swain, A. (1995). Predisposition to experience debilitative and facilitative anxiety in elite and nonelite performers. The Sport Psychologist, 9, 201-211.

Lewthwaite, R., \& Wulf, G. (2010). Social-comparative feedback affects motor skill learning. The Quarterly Journal of Experimental Psychology, 63, 738-749. doi:10.1080/17470210903111839

Maas, E., Robin, D. A., Hula, S. N. A., Freedman, S. E., Wulf, G., Ballard, K. J., \& Schmidt, R. A. (2008). Principles of motor learning in treatment of motor speech disorders. American Journal of SpeechLanguage Pathology, 17, 277-298. doi:10.1044/1058-0360(2008/025)

Magill, R. (2011). Motor learning: Concepts and applications. New York: McGraw-Hill.

Moulton, C.-A.E., Dubrowski, A., MacRae, H., Graham, B., Grober, E., \& Reznick, R. (2006). Teaching surgical skills: What kind of practice makes perfect? A randomized, controlled trial. Annals of Surgery, 244, 400-409.

Onla-or, S., \& Winstein, C. J. (2008). Determining the optimal challenge point for motor skill learning in adults with moderately severe Parkinson's disease. Neurorehabilitation and Neural Repair, 22, 385-395. doi: $10.1177 / 1545968307313508$

Schmidt, R. A., \& Wrisberg, C. A. (2008). Motor learning and performance: A situation-based learning approach. Champaign, Human Kinetics.

Spielberger, C. D. (1972). Anxiety: Current trends in theory and research. Oxford, England: Academic Press.

Spielberger, C. D., Gorsuch, R. L., Lushene, R. E., Vagg, P. R., \& Jacobs, G. A. (1983). Manual for the state-trait anxiety inventory. Palo Alto, CA: Consulting Psychologist Press.

Weinberg, R. S., \& Gould, D. (2011). Foundations of sport and exercise psychology. Champaign, Human Kinetics.

Wrisberg, C. A. (2007). Sport skill instruction for coaches. Champaign, Human Kinetics.

Wulf, G., \& Toole, T. (1999). Physical assistance devices in complex motor skill learning: Benefits of a self-controlled practice schedule. Research Quarterly for Exercise and Sport, 70, 265-272. 